\title{
Pulmonary Hemorrhage due to Pulmonary Venous Occlusion after Radiofrequency Catheter Ablation for Atrial Fibrillation
}

\author{
Masamichi Hayashi ${ }^{a}$ Tomoyuki Minezawa $^{a} \quad K^{2}$ azuyoshi Imaizumi ${ }^{a}$ \\ Yoshihiro Sobue $^{b}$ Eiichi Watanabe $^{\mathrm{b}}$ Yukio Ozaki $^{\mathrm{b}}$ Mitsushi Okazawa $^{\mathrm{a}}$ \\ ${ }^{a}$ Division of Respiratory Medicine and Clinical Allergy, Department of Internal Medicine, and \\ ${ }^{b}$ Department of Cardiology, Fujita Health University, Toyoake, Japan
}

Case 1, a 45-year-old male ex-smoker, was referred to our clinic because of persistent hemoptysis and pulmonary infiltration in the left upper lobe for 2 months (fig. 1), which were not responsive to several antibiotic treatments. He had undergone radiofrequency pulmonary vein (PV) ablation twice for a paroxysmal atrial fibrillation (AF) and was taking anticoagulation therapy with warfarin after the ablation. Bacteriological tests were all negative. Bronchoalveolar lavage and transbronchial biopsy showed pulmonary hemorrhage with numerous phagocytic macrophages of red blood cells. A 3D image of contrast cardiac CT showed occlusion of the left upper trunk of the PV (fig. 2).

Case 2, a 21-year-old male non-smoker, who had a history of dilated cardiomyopathy and persistent AF, had undergone PV ablation. Three months after treatment, he showed slight elevation of body temperature and pulmonary infiltration in CT, and later hemoptysis. Hematological examination showed slight elevation in C-reactive protein and increased D-dimer and fibrinogen levels. Bacteriological examinations were all negative. Contrast cardiac CT showed occlusion of the branch of the right upper PV trunk (fig. 3), where there was pulmonary infiltration. He was on anticoagulation therapy with dabigatran.

\section{KARGER}

E-Mail karger@karger.com www.karger.com/res

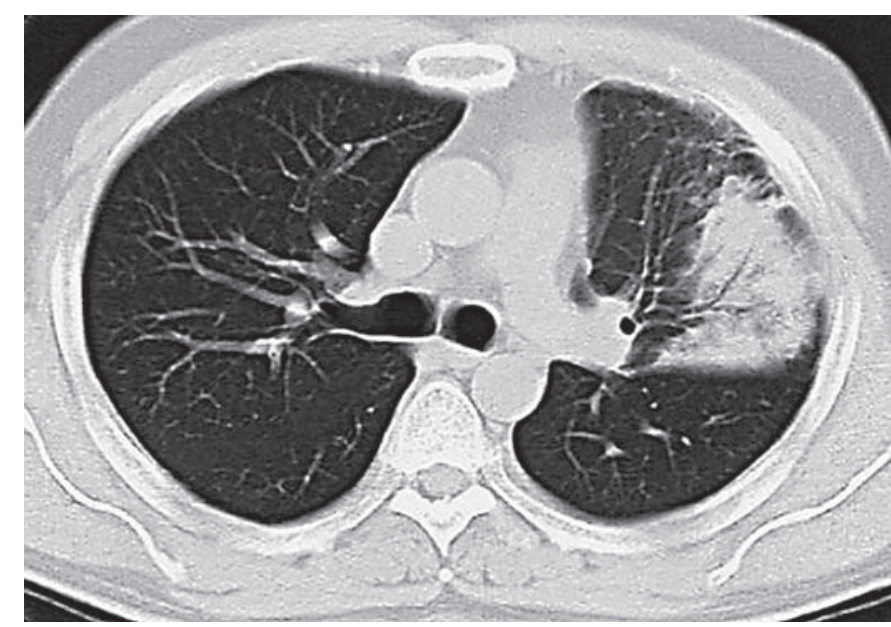

Fig. 1. CT showing pulmonary infiltration in the left upper lobe.

A recent worldwide survey reported that the frequency of PV stenoses requiring intervention was $0.29 \%$ [1]. Packer et al. [2] reported that only 1 case had hemoptysis in 23 patients with PV stenosis after ablation. An early diagnosis using multi-detector cardiac CT or dynamic MRI after ablation is the diagnostic modality of choice. Although angioplasty was not applied in either case, the

Mitsushi Okazawa, MD, PhD

Division of Respiratory Medicine and Clinical Allergy, Department of Internal Medicine Fujita Health University

Toyoake 470-1165 (Japan)

E-Mail mokazawa@ fujita-hu.ac.jp 


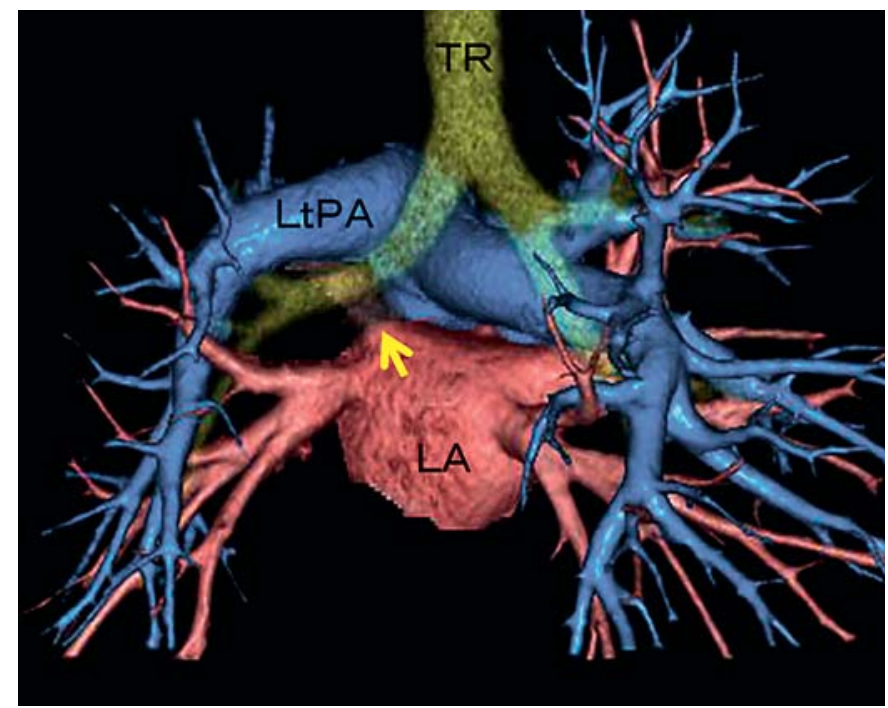

Fig. 2. 3D image of contrast cardiac CT (posterior view). The left upper trunk of the PV is occluded (arrow). TR = Trachea; LtPA = left pulmonary artery; LA = left atrium.

treatment options for extensive PV stenosis and occlusions could primarily be PV angioplasty either by catheter dilatation or cardiac surgery. Both our patients had a single PV stenosis, whereas an increasing number of PV trunk stenoses which require additional intensive anticoagulant therapy might potentially lead to a fatal parenchymal hemorrhage.

In conclusion, although $\mathrm{PV}$ occlusion is a rare complication [1], this condition should be taken into account when pulmonary infiltration or hemoptysis appears after PV ablation for AF.

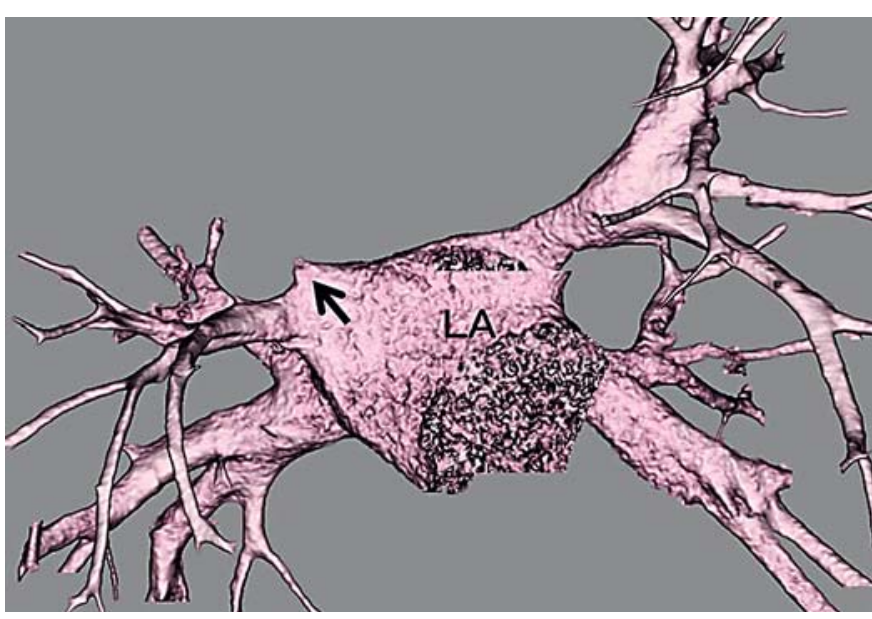

Fig. 3. 3D image of cardiac CT (anterior view) showing occlusion of the branch of the right upper pulmonary venous trunk (arrow). $\mathrm{LA}=$ Left atrium.

\section{References}

1 Cappato R, Calkins H, Chen S-A, Davies W, Iesaka Y, Kalman J, et al: Updated worldwide survey on the methods, efficacy, and safety of catheter ablation for human atrial fibrillation. Circ Arrhythm Electrophysiol 2010;3:32-38.

-2 Packer DL, Keelan P, Munger TM, Breen JF, Asirvatham S, Peterson LA, et al: Clinical presentation, investigation, and management of pulmonary vein stenosis complicating ablation for atrial fibrillation. Circulation 2005; 111:546-554. 